\title{
FORMAÇÃO DO PROFESSOR DA EDUCAÇÃO ELEMENTAR NO BRASIL: REFLEXÕES SOBRE O TEMPO E A EXPERIÊNCIA (1870-1950)
}

\author{
Domenica Martinez \\ Pontifícia Universidade Católica de São Paulo (PUC-SP), São Paulo, Brasil
}

\begin{abstract}
Resumo: O objetivo do artigo é estudar algumas transformações dos cursos de formação do professor para a educação elementar promovidos no Brasil, entre as décadas de 1870 e 1950, especialmente no que se refere ao tempo e à experiência, a partir de uma revisão histórica inicial, com base em pesquisa bibliográfica e documental. São destacadas as contradições desses conceitos, especificamente, quanto às aceleradas e interpostas extensão e alterações curriculares da formação docente à promoção da escola para todos, de características, sobremaneira, técnico-instrumentais.

Palavras-Chave: Formação do professor. Educação elementar brasileira. Tempo. Experiência.
\end{abstract}

INTRODUÇÃO

O presente artigo visa contribuir com reflexões acerca das transformações da formação do professor brasileiro, especificamente no que se refere às alterações sobre a acepção do tempo e das possibilidades de experiência para a autorreflexão que determinam, ao passo que são determinadas, pela ordem e organização particulares da sociedade moderna. Trata-se de uma revisão inicial feita por meio de estudo bibliográfico e de documentos legais, com o objetivo de compreender as alterações que as concepções sobre o 
tempo e a experiência têm sofrido historicamente, na formação do professor, em especial entre as décadas de 1870 e 1950, período em que há uma significativa expansão das Escolas Normais no país; é, portanto, um apanhado de alguns textos que tratam do assunto e de algumas leis educacionais promulgadas durante um intervalo de oito décadas, de modo a não esgotar o assunto, propiciando ao leitor fontes básicas acerca do assunto. $O$ escopo é apresentar as objetivações do tempo e da experiência tomando-se por referência os métodos, matérias e suas distribuições no currículo das escolas de formação de professores voltados à educação elementar, compreendendo o professor como o profissional que passa ser o responsável pela instrução geral do indivíduo; por isso, justifica-se a atenção por esses profissionais que propiciam experiências às crianças e aos jovens formados pela educação escolar orientada por objetivos econômicos, políticos e culturais. Ademais, visa indicar alguns aspectos das determinações históricas da formação do professor brasileiro, considerando o desenvolvimento econômico do país, atrelado, assim como a própria gênese da instrução escolar para todos, aos desdobramentos do sistema de produção capitalista concomitantes à expansão do conhecimento e, consequentemente, à necessidade que se coloca de flexibilidade da instrução escolar, sobremaneira técnico-científica.

No que segue, o texto é apresentado em dois momentos: o primeiro expõe os principais resultados do que se obteve a respeito das transformações sobre o tempo e a experiência da formação e do trabalho docente na sociedade europeia do período mencionado; em um segundo momento, essas transformações são apresentadas estritamente na sociedade brasileira.

FORMAÇÃO E TRABALHO DOCENTE SOB O LIBERALISMO: ESCOLA MODERNA, TEMPO E EXPERIÊNCIA

A formação constitui-se como finalidade de toda prática educativa, sendo realizada de modo sistemático ou assistemático no decorrer da história da civilização como meio de transmissão de valores, costumes, hábitos, condutas e conhecimentos. As características da prática educativa são alicerçadas socialmente, conforme, em cada época, é concebida a ma- 
neira pela qual os sujeitos melhor se adaptam, conhecem e desenvolvem esses valores, costumes, hábitos, condutas e conhecimentos para agirem socialmente desde a infância. Seja em grupos sociais primários, tal como a família, seja em vínculos sociais institucionalizados como os promovidos pela escola, pelas organizações religiosas, bem como pelas instituições voltadas às atividades produtivas, são o desenvolvimento técnico, os valores éticos, as regras morais, o gosto estético, instituídos como cultura os provedores dos princípios que determinam a formação. Nesses termos, a formação é a base que sustenta e transforma, de geração a geração, um grupo social por meio do que é possibilitado para a apropriação subjetiva da cultura (ADORNO, 1996). Ao nascer, o sujeito é levado a se adaptar e, consequentemente, a transformar as condições sociais em que se encontra, de modo que a relação entre indivíduo e sociedade é determinada, em primeira instância, pelas ações individuais que o meio social suscita. Dessa relação são consubstanciadas a socialização inicial da criança, a educação geral assentada em mediações sociais denominadas de instituições e, a partir ainda da primeira infância, a formação é compartilhada, na sociedade moderna, pela educação escolar e pelo ensino, quando passa a se destacar a finalidade do trabalho docente.

No decorrer da história, a formação passou a fazer parte das principais questões sociais, destacando-se nos últimos séculos como meio para a promoção das dimensões econômicas, políticas e culturais. Essa tendência é em parte resultante do homem situado como ser livre e racional, responsável por sua própria existência frente à natureza. Essa condição expandida às distintas esferas da produção material e da cultura atinge a todos os homens, instituições sociais, segmentos sociais e categorias de trabalhadores, o que inclui a escola e o trabalho docente, ainda que de maneira diferençada. $\mathrm{O}$ trabalho do professor carrega os traços da tendência racional com a qual a condição do homem passa a ser compreendida, de modo que, para analisar sua atividade concreta torna-se imprescindível considerar, por um lado, que os aspectos psíquicos e sociais são entrelaçados e, por outro, as implicações do uso da razão para a formação do próprio professor. Esse entendimento converge com aquele sintetizado por Adorno (1986, p. 43): 
Enquanto as leis sociais não podem ser "extrapoladas" a partir dos traços psicológicos, o indivíduo, no pólo contrário, não é simplesmente indivíduo e substrato da psicologia, senão sempre e a cada vez - enquanto se comporta racionalmente de alguma maneira - portador das determinações sociais que o selam.

O excerto acima corrobora para o entendimento sobre a procedência em levar em conta a conexão entre indivíduo e sociedade quando se coloca em questão a formação do indivíduo, da consciência, historicamente determinadas pela ascensão da sociedade administrada, de modo que, para compreender as esferas individual e social da sociedade moderna, ambas devem ser consideradas de maneira inextricável, como decorrentes do processo de racionalização das relações humanas imanentes ao capital.

Nesses termos, as alterações da noção do tempo sobre a formação docente são analisadas em relação à experiência, compreendida como relativa ao que é expressado pelo indivíduo, caracterizada pelo que ele é por meio do que faz e, assim, como pode viver frente à natureza e à sociedade, uma vez determinado pelas condições materiais e sociais em que vive. O tempo e a experiência são elementos indissociáveis da formação da consciência e determinam as possibilidades de atitudes e ações reflexivas (MARTINEZ, 2013).

A relação entre consciência, tempo e experiência pode ser compreendida como a manifestação do sujeito, considerando-se o tempo socialmente estabelecido em que ele vive e o tempo como a forma do pensamento que lhe é possibilitado; correspondência entre o tempo e a consciência. A consciência reflexiva, possível pela experiência, vincula-se a um tempo para o pensamento sobre a ação que o determina para, sucessivamente, orientar as atitudes do indivíduo; caso contrário, a ação que ocorre sem um tempo suficiente para a assimilação daquilo a que o sujeito reage por meio da articulação dos estímulos no pensamento tende a impedir a experiência formativa pela autorreflexão (MEAD apud SASS, 2004). A temporalidade do pensamento pode ser notada como aquele tempo suficiente em relação à consciência reflexiva, de maneira que a compreensão sobre o tempo pelo sujeito determina suas intenções, manifestando-se pela reflexão sobre essas intenções erigidas das marcas do passado rumo ao presente e futuro. O fluxo do tempo é percebido pelo 
sujeito por meio das experiências suscitadas quando sentidos e expressados os aspectos - de ordens qualitativa e quantitativa, material e temporal - dos objetos e das situações com os quais o sujeito entra em contato. A consciência sobre o fluxo do tempo está relacionada, assim, à apropriação dos conteúdos retidos na memória no ato da experiência; “onde há experiência no sentido estrito do termo, entram em conjunção na memória, certos conteúdos do passado individual com outros do passado coletivo" (BENJAMIN, 1994, p. 207). Destarte, compreender esses conceitos como determinados e determinantes de fatores externos, objetivos e mecanismos internos, psíquicos aos indivíduos, orienta a análise para considerações acerca de relações entre tempo, experiência, memória e consciência.

Os movimentos que efetivaram a tendência racional do pensamento e das relações sociais, e que alteram as noções de tempo e experiência, podem ser observados como decorrentes de fatores acentuados desde o século XVI e efetivados como convenções no século XVIII, dos quais se destacam o sistema econômico capitalista e o ideário liberal, com as características e resultados sobre a organização da sociedade. Para elucidar as implicações desses movimentos sobre a formação que repercutem no trabalho docente, especialmente, por meio do controle objetivo e subjetivo do tempo, são indicadas algumas das transformações sociais tendo em vista a concepção iluminista. Ainda que possa ser de conhecimento geral é importante ressaltar, que, em decorrência dessa concepção, bem como das condições materiais que a sustentava, a escola contemporânea foi instalada e idealizada e o trabalho do professor passou a fazer parte das preocupações políticas; quando a formação passa a ser caracterizada como um processo sistemático promovido com os objetivos de universalizar o acesso ao conhecimento e promover uma sociedade racionalmente organizada, em que o sucesso individual é, de maneira imanente, vinculado ao sucesso produtivo do sujeito.

O movimento do lluminismo corresponde a um período histórico em que o homem passa a empenhar-se para alcançar uma relativa libertação, especialmente possível pelos avanços técnicos e científicos investidos no modo de organização social e de convicções culturais. O homem situa-se como ente central da realidade ao passo que cria e tem em mãos ferramentas 
que Ihe permite dominar a natureza, a qual, outrora, se lhe apresentava como superior. Dotado das luzes da razão o sujeito passa a ser o principal elemento do cognoscível, condição que leva a ser destacadas questões acerca de como o sujeito conhece, bem como o que se pode fazer para a expansão universal do conhecimento. $\mathrm{O}$ sujeito toma-se definitivamente como objeto, bem como a natureza que o cerca; o pensamento passa a ser dirigido tanto para os objetos externos quanto para si mesmo como objeto de reflexão, sendo: o instrumento que medeia essa relação, a racionalidade; o operador desse instrumento, o sujeito; e o objetivo da operação, o esclarecimento universal da humanidade por meio do rompimento de seu encantamento religioso, ou, enfeitiçado com a natureza.

Nessas condições, para consolidar uma nova base política-econômica por preceitos liberais em detrimento do capital aplicado à indústria, no que se refere à educação, em um primeiro momento, o movimento burguês vencedor tratou de garantir o acesso à instrução escolar universal, pública, laica, científica e racional a passos tão largos e sistematicamente configurados como os da marcha industrial (CAMBI, 1999; MANACORDA, 1989). Essa sistematização, porém, não foi feita sem contradições, de modo que, por um lado, havia defensores de uma educação voltada estritamente à aristocracia, como aquelas traçadas por Rousseau e Voltaire, na França e, de outro lado, havia a reivindicação de uma educação voltada a todos, embora, para a classe menos abastada a educação deveria ser propagada em nível elementar de modo a manter a ordem social, como a manutenção e efetivação da proposta educacional elaborada por Comenius, que visava à elaboração de uma didática que capacitasse os indivíduos ao ensino de tudo para todos (CAMBI, 1999).

Essas contradições perpassavam por outro aspecto que pairava nesse campo de disputa entre os que visualizavam e concretizavam a expansão da educação laica, pública, universal e obrigatória: o método de ensino. A respeito das mudanças e discussões que ocorreram no século XIX, entre os que propugnavam a reforma e outros que resistiam, lançando mão de propostas didático-pedagógicas, explicita Manacorda (1989, p. 279):

Esta disputa atinge todos os níveis da instrução, das escolas infantis, que exatamente neste período começam a difundir-se, às escolas elementares, para 
as quais se discute o novo método do ensino mútuo, às escolas secundárias, que já vêm se articulando em humanísticas e científico-técnicas, às universidades, com suas novas faculdades correspondentes às transformações das forças produtivas. Esta disputa talvez tenha na questão do 'método' a ser usado nos primeiros níveis de instrução a sua expressão mais característica: podemos afirmar que, após a primeira grande idade da didática, aberta pela invenção da imprensa e pelas iniciativas dos reformados, com a grande figura de Comenios, esta nova idade da difusão da instrução às classes populares, do nascimento da escola infantil, da difusão dos livros de texto, das novas escolas para a formação dos professores, assinala um macroscópico retorno à pesquisa didática.

Observa-se que, entre as principais alterações, destaca-se a difusão da instrução escolar para as classes populares, a preocupação com a educação infantil e a formação de professores. Em particular, descrevendo o desenvolvimento de escolarização francesa do século XIX, Enguita (1989, p. 16) afirma que o objetivo da escola pública, voltada ao povo, era "ter os alunos entre as paredes da sala de aula submetidos ao olhar vigilante do professor o tempo suficiente para domar seu caráter e dar forma adequada ao seu comportamento". Segundo Thompson (2002), na ascensão industrial inglesa, a instituição escolar era usada para inculcar o uso econômico do tempo, formando para o trabalho. Os padrões da organização escolar seguiam a disciplina pelo controle do tempo: as aulas, entradas e saídas eram monitoradas minuto a minuto, assim como ocorria nas indústrias. A escola, nos meados do processo de industrialização, "reproduz sob múltiplas formas a divisão do trabalho imperante na sociedade" [...], sendo "a sua própria divisão interna" uma das formas elementares dessa reprodução (ENGUITA, 1989, p. 199). Nesses termos funcionava, junto de dispositivos externos, tais como "a divisão social do trabalho, multas, sinos e relógios", como uma instituição propensa a disseminar a disciplina para o comprometimento com o trabalho e pontualidade; atitudes necessárias para instaurar uma nova organização social arraigada no controle sistemático da produção, em que "todo tempo deve ser consumido, negociado, utilizado [...], sendo uma ofensa que a força de trabalho meramente 'passe o tempo'"' (THOMPSON, 2002, p. 298, grifo do autor). 
Contudo, é importante frisar que, embora, a escola tenha seguido em alguns aspectos a disciplina pelo controle do tempo, essa exigência provinha das necessidades dos mestres que tinham seus objetivos a atingir, isto é, transmitir certos conhecimentos instituídos como conteúdos (disciplinas). Considerando a impetuosidade das crianças e dos jovens tomando consciência de si frente aos mais velhos, a autoridade da família passa a ser deslocada para a escola, sob a figura dos mestres. A instituição de ensino consubstancia a autoridade de modo sistematizado tendo por respaldo a emergência do que passa a ser concretizado como a Pedagogia, as Ciências Sociais e a Psicologia.

Essas alterações provocadas pela promoção da instrução escolar propiciaram transformações no que se refere ao ensino. O primeiro impacto que os governantes tiveram que lidar decorrente da expansão do ensino foi a formação docente. Os professores, em geral, eram sujeitos que faziam do ensino um meio de sustento que não encontravam em outro lugar, tais como soldados, desempregados, inválidos de guerra, bem como jovens que ainda não haviam se colocado nos postos de trabalho. Ao mesmo tempo, a indisciplina ainda presente, com baixa frequência dos alunos e controle do ensino apresentava fatores de preocupação (CAMBI, 1999). Nesse sentido, é acentuada a necessidade do preparo dos professores, inclusive para a garantia das reformas sociais levadas adiante pelas revoluções burguesas.

Para responder aos ideais burgueses, em meados do século XIX são implementadas as Escolas Normais, distinguidas entre escolas Superiores voltadas à formação de professores para o ensino secundário e as escolas Primárias para os professores do ensino primário, em vários países da Europa. Sob o desenvolvimento de Estados-nação, estratégias pedagógicas são postuladas a fim de garantir o preparo dos responsáveis do ensino elementar de modo que fosse suficiente para universalizar e normalizar a formação dos indivíduos. Naquele período em que se efetivava o questionamento aos absolutismos da igreja católica e do feudalismo, somados às revoluções sobre o conhecimento pela ciência expandida às áreas sociais, a formação docente emerge como preocupação da ordem política governamental institucionalizada.

Dessas considerações desdobram-se duas ponderações: a primeira refere-se ao fato de que o tempo, como mediação da educação escolar, passar 
a ser determinante na função da escola e do trabalho docente. Isso porque o tempo se circunscreve nos propósitos da educação formal em correspondência com o desenvolvimento da organização social orientada pelas premissas liberais e, marcadamente, a partir do século XIX, com as forças desenvolvidas no processo de industrialização. Desse modo, a formalização do tempo escolar apresenta características contraditórias, acompanhando os moldes da lógica liberal no que é progressiva e regressiva à ordem social. Tais contradições manifestam-se à medida que a instituição escolar permite ou impossibilita uma formação que se estenda além dos laços sociais primários, como a família, bem como no que promove uma instrução dirigida à aprendizagem de conteúdos e destrezas que permitem aos sujeitos agirem conscientemente acerca do que produzem no que se refere a conhecimentos e qualificações técnicas. Cabe ressaltar, assim, as esperanças de liberdade contraditórias pelas quais o objetivo da educação escolar e o trabalho docente foram cunhados em sua origem: para a promoção de uma consciência livre, decorrente de uma formação específica e, para isso, estabelece normas pelas quais é possível administrar o processo de ensino e aprendizagem de maneira racional.

A escola emerge com propósitos de ordenar o espaço público, mas, tardiamente, é reformulada por ideais libertários com propósitos universais. Nesse sentido, se a escola é demarcada como uma instituição organizada para apropriação e produção de conhecimentos, orientada por elaborações científicas e estratégicas com fins sociais e políticos que determinam comportamentos e ordens sociais (DURKHEIM, 1964), pode fazer de seus objetivos tanto potencialmente libertadores, como limitadores do desenvolvimento das capacidades humanas.

A segunda ponderação a ser destacada é quanto à importância da presença do professor como profissional transformador das mudanças sociais decorrentes da formação escolar, especialmente, pela abertura à instrução institucionalizada pelo fomento à educação elementar. Isso indica que investigar a atuação do professor, bem como suas condições de trabalho, permite averiguar o modo como o ensino institucionalizado reproduz a ordem social, uma vez que quaisquer alterações sociais que a escola pode promover perpassam, em última instância, pela atuação docente. 
Para aprofundar essas duas ponderações passa-se ao segundo momento deste artigo, em que são enfatizadas as transformações da educação no Brasil no que se refere à formação e ao trabalho docente relacionados ao tempo e à experiência do professor circunstanciados à expansão do ensino no país.

TEMPO E EXPERIÊNCIA DE FORMAÇÃO DO PROFESSOR BRASILEIRO (1870-1950)

No período da Primeira República, especificamente após a oficialização da independência brasileira, as escolas voltadas à formação de professores são instaladas, ainda que de modo intermitente, uma vez que não havia um padrão formativo, sobretudo, no que se refere ao preparo pedagógico-didático, prevalecendo o método do ensino mútuo aos custos dos próprios professores (SAVIANI, 2009). As ações sobre a formação docente eram efetivadas pelas necessidades de intervenção governamental sobre a educação que passam a ser observadas pela responsabilização das províncias em adotar os projetos educacionais que seguiam os países europeus, especificamente, pelo desenvolvimento do sistema francês, com a criação de Escolas Normais concomitante às tentativas de implementação do ensino público elementar.

Acerca da base curricular da formação de professores pelas tentativas de instalação da Escola Normal e as práticas pedagógicas por ela delineadas, em período anterior ao que se ocupa o presente artigo, mas, é válido salientar considerando base desta análise, essas determinaram a concretização da administração e racionalização do tempo nas escolas primárias. Pode-se indicar como fatores as ações políticas de extensão do ensino e, também, a colaboração dos professores para a organização pedagógica, sob conflitos entre o Estado e a Igreja (Católica Apostólica Romana), sendo o tempo na escola brasileira, também, um amálgama fundamental para que a administração escolar fosse aprimorada para a universalização do ensino, no que se referia às exigências de frequência e ao calendário escolar (NAGLE, 1976; GALLEGO, 2008).

Do que se apreende como as primeiras tentativas à promoção da formação docente no país, nota-se a urgência transposta aos insucessos da instalação das Escolas Normais, decorrentes das incipientes condições econômicas e culturais, insuficientes para o desenvolvimento industrial 
acelerado que movimentava as transformações sociais vindas desde as revoluções industrial e burguesa. O método do ensino mútuo, ou Lancaster, desenvolvido na Inglaterra entre o final do século XVIII e início do século XIX, por Andrew Bell (1726-1809) e Joseph Lancaster (1778-1838), em momento de crescente urbanização frente às reformas protestantes, tinha por objetivo "diminuir as despesas da instrução, a abreviar o trabalho do mestre e a acelerar os progressos do aluno" (BELL apud MANACORDA, 1989, p. 257). O método de ensino mútuo, referendado por Bell e Lancaster, ilustra as bases do projeto formativo voltado à instalação dos ideais liberais, concretizados à medida que o sistema econômico capitalista é impulsionado e expandido em escala internacional. A variável tempo torna-se cada vez mais central, e racionalmente controlada, às concepções de indivíduo e sociedade manifestas em tal concretização, em que vida e trabalho produtivo passam a ser o norte para o motor da sobrevivência humana; time's money registra o peculiar slogan do atual modo de produção (WEBER, 2004), fazendo da energia humana um apêndice do motor industrial, ainda que o propósito fosse o da libertação dos homens frente à natureza e a si mesmos.

Em especial, sobre o currículo da formação docente, bem como ao ingresso no magistério brasileiro, destaca-se o declínio do método Lancaster, e a substituição do ensino misto, ou ensino individual, progressivamente pela pedagogia ativa da Escola Nova, que "penetram" o ideário educacional, passíveis de serem desenvolvidos à medida que as bases econômicas e políticas nacionais referendadas em movimentos internacionais europeus e norte-americanos são desenvolvidas, devido à expansão da escola primária sob os ideais liberais escolanovistas (NAGLE, 1976). Daquele período, até meados da década de 1850, observa-se que as transformações sobre a administração do tempo, desenvoltas entre convenções conflitantes sagradas e laicas, relaciona-se à organização escolar de modo a contribuir para o progresso da instrução, bem como para a subsunção do magistério sob o aparato governamental. A partir da década de 1860, a formação do magistério no Brasil, realizada por diversas tentativas de expansão das Escolas Normais, segue como desdobramento da lógica das ações imperiais, como uma apropriação dos domínios do ideário liberal, em difusão intercontinental desde as coroas europeias. 
No período dos anos de 1870 a 1890, houve uma reorganização social do que se sobre a formação docente, marcadamente em relação à expansão das Escolas Normais no país. Observa-se que o que se realiza são precedentes do movimento escolanovista, em contraposição à educação tradicional, em que pese todas as suas fases de desenvolvimento, destacando-se a reforma Leôncio de Carvalho promulgada em 1879. Sobre o currículo das Escolas Normais nota-se "críticas implícitas ou explícitas à escola tradicional, não [como] elemento novo que, ao ser adotado, provocava alterações importantes no funcionamento das instituições escolares" (NAGLE, 1976, p. 243). O ensino das "lições de cousas", por exemplo, não se apresentava como um método geral, mas, como disciplina do currículo das Escolas Normais; ao passo que o ensino passa a ser individualizado, o currículo passa a ser pautado em matérias científicas, em que o sujeito do aprendizado é o centro do ensino. Quanto aos anos de formação não são mencionados, apenas destacados no Artigo 9०, $\S 3^{\circ}$ "As disciplinas que constituem o programma das Escolas Normaes serão divididas em series, conforme a ordem lógica de sua successão" (BRASIL, $1879, \mathrm{~s} / \mathrm{p}$.); e a respeito das disciplinas, totalizam 26 , sendo que, nomeadas pelas áreas do conhecimento, observa-se destaque para o que atualmente pode-se chamar de Ciências Humanas e Sociais e Artes e Ofícios (Apêndice 1).

Entre os anos de 1890 e 1932 há um reconhecimento da ineficácia do ensino e da insuficiência da formação dos professores diante da expectativa educacional em formar brasileiros em consonância com o progresso científico e moderno. Nesse âmbito, as Escolas Normais passam por reforma iniciada no Estado de São Paulo, promulgada pelo Decreto n 27, de Março de 1890, “marcada por dois vetores: o enriquecimento dos conteúdos curriculares anteriores e ênfase nos exercícios práticos de ensino" (SAVIANI, 2009, p. 145). No que se refere às "aspirações e nas proposições teóricas efervescentes na fase final do regime monárquico, já encontrara o seu lugar a tese de que o professorado merecia preparo regular" (TANURI, 2000, p. 67). Ademais, a associação entre o processo civilizatório e os progressos nacional e internacional pode ser sublinhada pelos "entusiasmo pela educação" e "otimismo pedagógico", que se concretizam em meados de 1920 (NAGLE, 1976). Consolidando a estrutura de um país, que determinado a acompanhar a ascensão do sistema econômico 
industrial-capitalista, em que o crescimento das indústrias e do mercado afirma-se importante no cenário mundial, encontra-se como caminho para tal empreitada a expansão sistemática do ensino primário, bem como do secundário, instalando-se o reconhecimento da necessidade de administração do ensino profissionalizante. Das 17 matérias, número bem menor do que até então eram assinaladas, destacam-se as Ciências Exatas, distribuídas em três anos, e não havendo qualquer menção às práticas de ensino (BRASIL, 1890).

No que diz respeito à extensão e ao currículo da instrução elementar e normal nesse período, "situam-se, além da unificação, o aumento do número de anos de formação, com a criação dos cursos complementares como intermediários entre o primário e o normal, em 1917, com dois anos de duração, elevados para três em 1920" (TANURI, 2000, p. 69). Especificamente, na Escola Normal, houve transformações significativas, destacando-se "a amplitude do currículo, com ênfase nas matérias científicas, o prolongamento de seu curso para quatro anos, e a exigência de uma cultura enciclopédica, a ser avaliada através de exames, para ingresso na referida instituição" (TANURI, 2000, p. 69).

Do exposto, destaca-se o sucedâneo à instalação da escola para todos; uma vez cerceada de novos conhecimentos em distintas áreas, como energia humana despendida atravessada pelo avanço técnico-científico e industrial, nas primeiras décadas do século $\mathrm{XX}$, as preocupações com a formação escolar, em que se inclui a formação docente, a organização escolar passa a preocupar-se com o ensino profissional e especializado, indicando a necessidade de um maior período de formação, a fim de que prosperasse o desenvolvimento do sistema produtivo.

Tal expansão e organização sistemática e especializada do ensino passam a ser concretizadas e aprimoradas, tendo um marco em 1939, com a criação do curso de Pedagogia, derivado das inspirações de Anísio Teixeira e Lourenço Filho, no Distrito Federal, e de Fernando de Azevedo, em São Paulo, nos ideais da Escola Nova, instituindo para a formação dos professores, em primeiro momento, a Escola de Professores no lugar das Escolas Normais, e em sequência, entre 1934 e 1935, elevando os institutos educacionais ao nível universitário, aproximando a educação no âmbito da Faculdade de Filosofia, Ciências e Letras. Os diferenciais curriculares desses cursos era um modelo 
pedagógico-didático frutífero embasado em um ensino de humanidades e ciências, firmando o conhecimento dos professores em um caráter científico, em decorrência do que é efetivada a inclusão da História da Educação, da Sociologia, da Biologia e da Psicologia Educacional, além de literatura infantil e princípios e técnicas de ensino referendadas pelo ensino ativo e na psicologia experimental, tais como as de Ovide Decroly (1871-1932), Édouard Claparède (1873-1940), John Dewey (1859-1952), que assinalavam para a importância da criança como o centro do interesse do ensino em uma sociedade democrática e libertadora (SAVIANI, 2009). Essas modificações têm implicações sobre o tempo e sobre a experiência dos professores a serem preparados.

Firma-se como registro dessa época o Manifesto dos Pioneiros da Educação Nova (1932), assinado por pensadores que indicavam os propósitos educacionais um direito a todos, como um dever de promoção pelo Estado, visando à superação das "escolas espiritualistas" que desdenhavam a "multidão", evitando a experiência da sorte de todas as oportunidades do conhecimento, engajados na formação de homens que servissem "à humanidade [...] em comunhão com ela..." (AZEVEDO et al., 2010, p. 42).

Importa, ainda, destacar que essa ampliação é fruto do preparo de meados da década de 1930, quando as instalações educacionais passam a ser supervisionadas pela avaliação política e governamental trazendo questões sobre os próximos encaminhamentos da instrução escolar na "encruzilhada" entre a expansão e a qualidade do ensino primário e o processo de industrialização do país. Entre essas principais questões coloca-se como problema a necessidade do ensino propedêutico para o acesso ao ensino secundário frente às possibilidades de incremento do aparato industrial, como alavanca para o crescimento econômico do país, instando-se em seu lugar, a formação profissional, substancialmente prática, tendo-se por centro dos processos de ensino e aprendizagem o aluno, sendo este todo cidadão brasileiro.

Nota-se que desde a implantação da instrução escolar moderna, à medida que são instituídos os problemas de expansão e acesso, a organização curricular é alterada, sendo determinada pelo modo de produção industrial, que passa a demandar força de trabalho qualificada, sendo essas qualidades baseadas no desenvolvimento da autonomia do indivíduo. O que se sobressai 
do escolanovismo é o aluno quem decide, de acordo com seus "interesses", o que fazer, sendo o método científico o caminho para tanto, o qual exige que o ensino baseie-se na experiência inteligente tanto do aluno quanto do professor. Nessa medida, pode-se interpretar que a organização do tempo do trabalho docente passa a ser determinado, de certa forma, pelas ações dos alunos, em que a flexibilidade didático-pedagógica e maiores domínio de conhecimentos e disposições de energia são exigidos.

Identifica-se, diante dessas considerações, o desenvolvimento do racionalismo em voga desde o século $\mathrm{XVI}$, que propunha o alcance da evolução no tratado social do Estado por meio da objetividade e imparcialidade governamental. Consolidando a estrutura de um país que acompanha a ascensão do sistema econômico industrial-capitalista, nas décadas de 1930 e 1940, em que o crescimento das indústrias e do mercado afirma-se importante no cenário mundial, inclusive entre preceitos de empréstimos internacionais, encontrava-se como caminho a expansão sistemática do ensino e um acompanhamento técnico deste, expresso, largamente, em avaliações estatísticas. Essa organização sistemática, técnico-científica de expansão e avaliação continua a orientar a educação brasileira, apesar das reformulações ocorridas.

No que segue, destacam-se as transformações da formação do professor entre o final da década 1930 e toda a década 1950, período no qual também, estão presentes profundas transformações do projeto educacional, então, em voga no país. Os questionamentos sobre o "sistema educacional" começam a torná-lo visivelmente inadequado para o ensejo dos provimentos industriais abrindo brechas a oportunidades de intervenções tomando como pano de fundo os ideais da vanguarda escolanovista brasileira.

No que se refere à formação dos professores das escolas primárias e aos cursos normais, esta passa a ser iniciada em nível superior em meados de 1939, quando da efetivação do curso de Pedagogia, criado na Faculdade Nacional de Filosofia da Universidade do Brasil. Segundo Saviani (2009, p. 146), tem-se que:

o decreto-lei n. 1.190 [de 4 de abril de 1939] se estendeu para todo o país, compondo o modelo que ficou conhecido como "esquema $3+1$ "adotado na organização dos cursos de licenciatura e de Pedagogia. Os primeiros forma- 
vam os professores para ministrar as várias disciplinas que compunham os currículos das escolas secundárias; os segundos formavam os professores para exercer a docência nas Escolas Normais. Em ambos os casos vigorava o mesmo esquema: três anos para o estudo das disciplinas específicas, vale dizer, os conteúdos cognitivos ou "os cursos de matérias", na expressão de Anísio Teixeira, e um ano para a formação didática.

A distribuição disciplinar do currículo dos cursos para a formação do magistério naquele momento prosseguiu imbuída do ideário escolanovista, em marcha rumo à modernização do país, destacando-se o aumento dos anos de formação inicial docente, ainda que dividida entre formação geral para o bacharelado e específica, de modo reduzido, a licenciatura em caráter técnico-instrumental.

Destarte, desse último período referido neste trabalho, cabe ainda mencionar as alterações estabelecidas pela Lei Orgânica do Ensino Normal, oficializada sob o Decreto-Lei ${ }^{\circ} 8.530$, de 2 janeiro de 1946 . Sobre as disciplinas, encontra-se um número de 20, sendo a maior parte voltada às Ciências Humanas e Sociais, Artes e Ofícios e Práticas Pedagógicas, distribuídas em quatro anos, repetindo-se ao longo dos anos. Tal distribuição corrobora com a presente tese de que à medida que há a expansão do ensino, há, também a expansão da formação docente, sob argumentos de flexibilização do aprendizado e, por sua vez, sob domínios técnicos instrumentais das áreas do conhecimento pelo professor.

Em resposta às expansões da efetivação contrária ao modo de produção capitalista concentrada em algumas nações, em que o sistema encontrava-se mais desenvolvido, de um lado pela lógica liberal e, por outro lado, também, ultrapassado por outras bases sociais desde o início do século XX, como aquelas objetivadas na Rússia, ainda sob a configuração da União das Repúblicas Socialistas Soviéticas, a história da civilização registra as Guerras Mundiais marcadas a contrapelo de disputas territoriais, religiosas, étnicas e, tardiamente, tecnológicas. Esses confrontos permanecem ao longo do século XX e no Brasil não deixaram de aparecer. Após o fim da Segunda Guerra Mundial, por meio de acordos internacionais, a formação docente passa a ser situada "no âmbito das metodologias de ensino, e com base na psicologia, objetivo esse que se estendeu também ao campo da supervisão 
e do currículo" (TANURI, 2000, p. 78), incentivada pelo Programa de Assistência Brasileiro-Americana ao Ensino Elementar (PABAEE), em vigor de 1957 a 1965, resultante de acordo entre o Ministério da Educação/Instituto Nacional de Estudos e Pesquisas (MEC/INEP) e a United States Agency for International Development (USAID). Resulta desses investimentos e planos a elevação dos problemas decorrentes da formação docente, estritamente técnica, de conteúdos direcionadores da moral e do civismo e voltados à profissionalização, de maneira que, apesar do aumento da carga horária de formação docente, o conteúdo estritamente funcional acarretaria contradições nas possibilidades de experiências à formação autorreflexiva do professor, sendo sua função mais de operacionalização do que elaboração e desenvolvimento do conhecimento. Em 1964, com o golpe militar no país, são catalisadas as apropriações progressistas das ideias culturais do projeto libertário iniciado das revoluções burguesas, permanecendo substantivamente o crescimento do modo de produção capitalista junto ao crescimento econômico da tendência administrativa propugnada em dimensão internacional.

\section{CONSIDERAÇÕES FINAIS}

A formalização do tempo escolar, também presente no processo formativo do professor, acompanha os moldes da lógica liberal no que é progressiva e regressiva à ordem social, deixando indícios das alterações da experiência formativa desse profissional. O ensino institucionalizado pela escola moderna destaca-se como libertário quando enseja a formação de homens conscientemente situados no mundo, adaptando-se e criando formas para nele agir concretizando perspectivas que orientem seu esclarecimento para ultrapassarem o que lhes é desfavorável; quando propugna que os objetivos da formação docente são voltados à formação de sujeitos livres e autênticos, contestadores dos entraves formativos suscitados de uma sociedade em que o conceito de liberdade seja plenamente compreendido. De outra parte, os problemas da educação escolar, presentes de maneiras distintas desde sua origem, indicam que "existe no conceito de educação para a consciência e para a racionalidade uma ambiguidade. Talvez não seja possível superá-la no existente, mas certamente não podemos nos desviar dela" (ADORNO, 
2003, p.144). Nesse sentido, o propósito deste artigo foi o de indicar o que orienta e desorienta as ações sociais para o que poderia ser superado, no que se refere ao tempo e à experiência do professor, pela formação inicial, compreendendo que a educação "tem sentido unicamente como educação dirigida à auto-reflexão crítica" (ADORNO, 2003, p.121).

Artigo recebido em: 11/12/2015 Aprovado para publicação em: 09/02/2016

\section{EDUCATION TEACHER TRAINING OF ELEMENTARY SCHOOL IN BRAZIL: REFLECTIONS ON TIME AND EXPERIENCE (1870-1950)}

Abstract: The goal of this article is to study some changes of teacher training courses for elementary education promoted in Brazil, between the 1870s and 1950s, especially with regard to time and experience; from an initial historical revision; based on a bibliographic and documental research. Some contradictions of these concepts are highlighted, specifically, regarding the accelerated and interposed extension and curricular changes in teacher training to school promotion for all, especially, of technical-instrumental features.

KEYWORDS: Teacher training. Elementary Brazilian education. Time. Experience.

\section{FORMACIÓN DE PROFESORES DE EDUCACIÓN ELEMENTAL EN BRASIL:} REFLEXIONES SOBRE EL TIEMPO Y LA EXPERIENCIA (1870-1950)

Resumen: El objetivo de este artículo es estudiar algunas transformaciones promovidas en Brasil para los cursos de formación del profesorado de la educación primaria, entre las décadas de 1870 y 1950, especialmente en lo que se refiere al tiempo y a la experiencia. Se parte de una revisión histórica y se fundamenta en una investigación bibliográfica y documental. Se destacan las contradicciones de esos conceptos, particularmente, sobre las aceleradas e interpuestas extensión y alteraciones curriculares de la formación del profesorado a la promoción de la escuela para todos, de características, especialmente técnico-instrumental.

Palabras-clave: Formación del profesorado. Instrucción elemental brasileña. Tiempo. Experiencia 
Apêndice 1 - Reformas educacionais, tempo, experiência no currículo

\begin{tabular}{|c|c|c|c|c|c|c|c|c|c|c|c|}
\hline \multirow[b]{2}{*}{ Retaras } & \multirow[b]{2}{*}{$\begin{array}{l}\text { Das do } \\
\text { Dectew }\end{array}$} & \multirow[b]{2}{*}{$\begin{array}{l}\text { Anov of } \\
\text { froma;io }\end{array}$} & \multicolumn{9}{|c|}{ 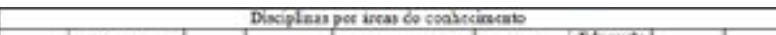 } \\
\hline & & & Lagus & $\begin{array}{c}\text { Menanase } \\
\text { Saciais }\end{array}$ & Exaras & Belogicas & $\begin{array}{l}\text { Detresto madia } \\
\text { \& Emino }\end{array}$ & $\begin{array}{l}\text { Antese } \\
\text { Ofiris: }\end{array}$ & $\begin{array}{c}\text { Elucasio } \\
\text { do } \\
\text { corpo }\end{array}$ & Fetidso & Theat \\
\hline $\begin{array}{l}\text { Enitiab do } \\
\text { Ceren } \\
\text { (Letedo } \\
\text { de } \\
\text { Carvilso) }\end{array}$ & $18 \%$ & 3 & 6 & 6 & 2 & 1 & 2 & 7 & $t$ & 1 & 26 \\
\hline $\begin{array}{l}\text { rects } \\
\text { Namal } \\
\text { (Cuntaso } \\
\text { de } \\
\text { caxpos) }\end{array}$ & 1600 & , & 1 & • & $s$ & I & ' & 2 & 2 & a & 17) \\
\hline 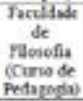 & 1939 & 3 & e & s & 2 & 1 & s & 0 & 0 & 0 & 14 \\
\hline $\begin{array}{c}16 \\
\text { Otfirica }\end{array}$ & 1945 & 4 & 1 & 6 & 2 & 3 & 3 & 4 & i & 0 & 20 \\
\hline
\end{tabular}

Fonte: elaboração própria, 2013.

\section{REFERÊNCIAS}

ADORNO, T. W. Acerca de la relación entre Sociologia y Psicologia. In: H. Jensen (Org.). Teoria crítica del sujeito. Buenos Aires: Sieglo XXI, 1986, p.36-83.

Teoria da semicultura. Educação \& Sociedade. Campinas, ano XVII, n.. 56, 1996, p. 389-411.

. Educação e emancipação. 3. ed. São Paulo: Paz e Terra, 2003.

AZEVEDO, F. et al. Manifesto dos pioneiros da Educação Nova. In: BRASIL/MEC-Fundação Joaquim Nabuco. Manifesto dos pioneiros da Educação Nova (1932) e dos educadores (1959). Coleção Educadores. Recife: Massangana, 2010, p.33-66.

BENJAMIN, W. Obras escolhidas. Magia e técnica, arte e política. SP: Brasiliense, 1994.

BRASIL. Decreto no 7.247, de 19 de Abril de 1879. Reforma o ensino primário e secundário no município da Corte e o superior em todo o Império. In: Coleção de Leis do Império do Brasil - 1879. V.1, pt. 2, p.196.

. Decreto $n^{\circ} 27$, de 12 de Março de 1890. Reforma a Escola Normal e converte em Escolas Modelos as Escolas annexas. Disponível em: <http://www.al.sp.gov.br>. Acesso em: 23 fev. 2016.

. Decreto-lei no 8.530, de 2 de Janeiro de 1946. Disponível em <http://www2. camara.leg.br>. Acesso em: 23 fev. 2016.

CAMBI, F. História da Pedagogia. São Paulo: UNESP (FEU), 1999.

DURKHEIM, É. A educação como processo socializador: função homogeneizaddora e função diferenciadora. In: PEREIRA, L, FORACCHI M. M. (Org.). Educação e sociedade: leituras de sociologia da educação. São Paulo: Editora Nacional; 1964. p. 34-69. 
ENGUITA. M. F. In: A face oculta da escola: educação e trabalho no capitalismo. Porto Alegre: Artes Médicas, 1989.

GALLEGO, R. de C. Tempo, temporalidade e ritmos nas escolas primárias públicas em São Paulo: heranças e negociações (1846-1890). Tese (Doutorado em Educação) Faculdade de Educação da Universidade de São Paulo, São Paulo, SP, 2008.

MANACORDA, M. A. História da educação: da Antiguidade aos nossos dias. São Paulo: Cortez/ Autores Associados, 1989.

MARTINEZ, D. Tempo, Experiência e trabalho docente: crítica da atividade do professor no Ensino Fundamental. Tese (Doutorado em Educação) - Pontifícia Universidade Católica de São Paulo, São Paulo-SP, 2013.

NAGLE, J. Educação e sociedade na Primeira República. Rio de Janeiro: DPA, 1976.

SASS, O. Crítica da razão solitária: a psicologia social segundo George Herbert Mead. Bragança Paulista: São Francisco, 2004.

SAVIANI, D. A nova lei da educação. LDB - trajetória, limites e perspectivas. Campinas: Autores Associados, 2009.

TANURI, L. M. História da formação de professores. Revista Brasileira de Educação, n. 14, p. 61-88, maio/ago. 2000.

THOMPSON, E. P. Costumes em comum. São Paulo: Companhia das Letras, 2002.

WEBER, M. A ética protestante e o espírito do capitalismo. São Paulo: Pioneira, 2004.

DOMEnica Martinez: Doutora e pós-doutoranda em Educação: História, Política, Sociedade; bolsista do Programa Nacional de Pós-Doutorado, da Coordenação de Aperfeiçoamento de Pessoal de Nível Superior (PNPD/CAPES); professora colaboradora junto ao Programa de Estudos Pós-Graduados em Educação: História, Política, Sociedade, na Pontifícia Universidade Católica de São Paulo (PEPG: EHPS/PUC-SP), desenvolvendo estudos junto à linha de pesquisa Teoria Crítica da Sociedade e formação: função social da educação e da escola.

E-mail: prof.domenica@smail.com 